\title{
A Step Toward Health Equity for Veterans: Evidence Supports Removing Race From Kidney Function Calculations
}

\author{
The Jesse Brown for Black Lives (JB4BL) Clinical Committee; Cheryl K. Conner, MD, MPH; Bijal Jain, MD; \\ Ambareen Khan, DO; Marci L. Laragh, MD; Sheryl Lowery, PharmD, BCPS; Natasha Nichols, MD; \\ Janine Steffan, MD; Jane K. Weber, MSN; and Samantha White, APRN
}

Background: The practice of race-based medicine fails to recognize that race cannot be used as a proxy for genetic ancestry and that racial and ethnic categories are complex sociopolitical constructs without biological basis. Clinical algorithms and equations that incorporate race modifiers and are currently considered standard for diagnosis and management of disease are appropriately being scrutinized for lack of biological plausibility and their role in exacerbating health inequities. In this paper, we review the history, evidence, and implications of using a Black race coefficient when calculating estimated glomerular filtration rate (eGFR) in the diagnosis and management of kidney disease.

Observations: Currently, the US Department of Veterans Affairs (VA) uses the Modification of Diet in Renal Disease (MDRD) equation for eGFR. This equation includes a Black race coefficient that results in an eGFR that is $21 \%$ higher for a Black patient when compared with a patient of any other race. The rationale for the inclusion of this coefficient is based on racist science that incorrectly assumes race as a proxy for genetic ancestry. Multiple studies across diverse Black populations demonstrate that the application of a race coefficient in kidney function estimation equations is inferior when compared with the race-neutral option. Furthermore, the most utilized eGFR equations are biased and imprecise. Because eGFR is the primary diagnostic method for detecting and managing kidney disease, preventing its progression, planning for dialysis, and evaluating for transplantation, it is vital that eGFR be as accurate, precise, and equitable as possible.

Conclusions: The incorporation of a race coefficient in kidney estimation equations lacks biological plausibility and its use exacerbates kidney health disparities. Until a better method to estimate kidney function becomes available, a race-neutral option for current estimation equations should be applied for all patients.
Author affiliations can be found at the end of the article.

Correspondence:

Marci Laragh

(marci.laragh@va.gov)

Fed Pract. 2021;38(8). Published online August 11. doi:10.12788/fp.0168
T he American Medical Association publicly acknowledged in November 2020 that race is a social construct without biological basis, with many other leading medical organizations following suit. ${ }^{1}$ Historically, biased science based on observed human physical differences has incorrectly asserted a racial biological hierarchy., Today, leading health care organizations recognize that the effects of racist policies in housing, education, employment, and the criminal justice system contribute to health disparities and have a disproportionately negative impact on Black, Indigenous, and People of Color. ${ }^{3,4}$

Racial classification systems are fraught with bias. Trying to classify a complex and nuanced identity such as race into discrete categories does not capture the extensive heterogeneity at the individual level or within the increasingly diverse, multiracial population. ${ }^{5}$ Racial and ethnic categories used in collecting census data and research, as defined by the US Office of Management and Budget, have evolved over time. ${ }^{6}$ These changes in classification are a reflection of changes in the political environment, not changes in scientific knowledge of race and ethnicity. ${ }^{6}$

\section{The Use of Race in Research and Practice}

In the United States, racial minorities bear a disproportionate burden of morbidity and mortality across all major disease categories. ${ }^{3}$ These disparities cannot be explained by genetics. ${ }^{4}$ The Human Genome Project in 2003 confirmed that racial categories have no biologic or genetic basis and that there is more intraracial than interracial genetic variation. ${ }^{3}$ Nevertheless, significant misapplication of race in medical research and clinical practice remains. Instead of attributing observed differences in health outcomes between racial groups to innate physiological differences between the groups, clinicians and researchers must carefully consider the impact of racism. ${ }^{7}$ This includes considering the complex interactions between socioeconomic, political, and environmental factors, and how they affect health. ${ }^{3}$

While race is not biologic, the effects of racism can have biologic effects, and advocates appropriately cite the need to collect race as an important category in 
epidemiological analysis. When race and ethnicity are used as a study variable, bioethicists Kaplan and Bennett recommend that researchers: (1) account for limitations due to imprecision of racial categories; (2) avoid attributing causality when there is an association between race/ethnicity and a health outcome; and (3) refrain from exacerbating racial disparities. ${ }^{6}$

At the bedside, race has become embedded in clinical, seemingly objective, decision-making tools used across medical specialties. ${ }^{8}$ These algorithms often use observational outcomes data and draw conclusions by explicitly or implicitly assuming biological differences among races. By crudely adjusting for race without identifying the root cause for observed racial differences, these tools can further magnify health inequities. ${ }^{8}$ With the increased recognition that race cannot be used as a proxy for genetic ancestry, and that racial and ethnic categories are complex sociopolitical constructs that have changed over time, the practice of race-based medicine is increasingly being criticized. ${ }^{8}$

This article presents a case for the removal of the race coefficient from estimated glomerular filtration rate (eGFR) calculations that exacerbate disparities in kidney health by overestimating kidney function in Black patients. ${ }^{8}$ The main justification for using the race coefficient stems from the disproven assumption that Black people have more muscle mass compared with non-Black people. ${ }^{9}$ The questioning of this racist assertion has led to a national movement to reevaluate the use of race in eGFR calculations.

\section{RACIAL DISPARITIES IN KIDNEY DISEASE}

According to epidemiological data published by the National Kidney Foundation (NKF) and American Society of Nephrology (ASN), 37 million people in the United States have chronic kidney disease (CKD).${ }^{10}$ Black Americans make up $13 \%$ of the US population yet they account for more than $30 \%$ of patients with end-stage kidney disease (ESKD) and $35 \%$ of those on dialysis. ${ }^{10,11}$ There is a 3 times greater risk for progression from early-stage CKD to ESKD in Black Americans when compared to the risk for White Americans. ${ }^{11}$ Black patients are younger at the time

\section{Clinical Vignette}

Mr. C is a 45-year-old veteran with a medical history of obesity, diabetes mellitus, hypertension, and chronic kidney disease stage 4 who presents to his primary care physician for routine follow-up. He recently read a news story about kidney function being assessed differently depending on whether the patient is a Black or White person. ${ }^{28}$ In the article, the Black patient would not have been listed for kidney transplant using standard estimating calculations that adjust for Black race.

Mr. C is particularly concerned about his advancing kidney disease and whether he will need a kidney transplant. He had a White mother and a Black father. He self-identifies as a Black man and others frequently would identify him as Black due to his complexion. He asks whether his race is being used when determining his kidney function, and how that could impact his health and the care he receives, including transplant referral. At most US Department of Veterans Affairs medical centers, the race coefficient would automatically be incorporated in estimating Mr. C's kidney function, which could have grave consequences for him.

of CKD diagnosis and, once diagnosed, experience a faster progression to ESKD. ${ }^{12}$ These disparities are partially attributable to delays in diagnosis, preventative measures, and referrals to nephrology care. ${ }^{12}$

In a VA medical center study, although Black patients were referred to nephrology care at higher rates than White patients, Black patients had faster progression to CKD stage $5 .{ }^{13}$ An earlier study showed that, at any given eGFR, Black patients have higher levels of albuminuria compared to White patients. ${ }^{14}$ While the reasons behind this observation are likely complex and multifactorial, one hypothesis is that Black patients were already at a more advanced stage of kidney disease at the time of referral as a result of the overestimation of eGFR calculations related to the use of a race coefficient.

Additionally, numerous analyses have revealed that Black patients are less likely to be identified as transplant candidates, less likely to be referred for transplant evaluation and, once on the waiting list, wait longer than do White patients. ${ }^{11,15}$

\section{Estimated Glomerular Filtration Rate}

It is imperative that clinicians have the most accurate measure of GFR to ensure timely diagnosis and appropriate management in patients with CKD. The gold standard for determining renal function requires measuring GFR using an ideal, exogenous, 
TABLE 1 Impact of Race Coefficient on eGFR

\begin{tabular}{lcc} 
Measures & Black & White \\
\hline Serum creatinine, mg/dL & 3.5 & 3.5 \\
\hline Age, y & 45 & 45 \\
\hline Gender & M & M \\
\hline $\begin{array}{l}\text { eGFR measures, mL/min/1.73m² } \\
\text { Modification of Diet in Renal Disease } \\
\text { Chronic Kidney Disease Epidemiology Collaboration }\end{array}$ & 23 & 19 \\
\hline
\end{tabular}

Abbreviations: eGFR, estimated glomerular filtration rate.

Results for Mr. C (Clinical Vignette), who is biracial and self-identifies as Black and for other self-identified Black veterans. To be listed for transplant, a patient must have eGFR $<20 \mathrm{~mL} / \mathrm{min} / 1.73 \mathrm{~m}^{2}$. If Mr. C were considered to be a Black veteran in the US Department of Veterans Affairs, he would not be referred for transplant; however, if he was considered to be a White man with the same serum creatinine, he would be referred for transplant services.

\section{CASE FOR REMOVING RACE COEFFICIENT}

When applied to cohorts outside the original study, both the MDRD and CKD-EPI equations have proved to be highly biased, imprecise, and inaccurate when compared to measured GFR (mGFR). ${ }^{15,17}$ For any given eGFR, the possible mGFR may span 3 stages of $\mathrm{CKD}$, underscoring the limitations of using such a crude estimate in clinical decision making. ${ }^{17}$

\section{Current Kidney Estimation Pitfalls}

A recent cohort study by Zelnick and colleagues that included 1658 self-identified Black adults showed less bias between mGFR and eGFR without the use of a race coefficient, and a shorter median time to transplant eligibility by 1.9 years. ${ }^{15}$ This study provides further evidence that these equations were derived from a biased observational data set that overestimates eGFR in Black patients living with CKD. This overestimation is particularly egregious for frail or malnourished patients with CKD and multiple comorbidities, with many potential harmful clinical consequences.

In addition, multiple international studies in African countries have demonstrated worse performance of eGFR calculations when using the race coefficient than without it. In the Democratic Republic of the Congo, eGFR was calculated for adults using MDRD with and without the race coefficient, as well as CKDEPI with and without the race coefficient, and then compared to mGFR. Both the MDRD and the CKD-EPI equations overestimated GFR when using the race coefficient, and notably the equations without the race coefficient had better correlation to mGFR. ${ }^{18}$ Similar data were also found in studies from South Africa, the Ivory Coast, Brazil, and Europe..$^{19-22}$

\section{Clinical Consequences of Race Coefficient Use}

The use of a race coefficient in these estimation equations causes adverse clinical outcomes. In early stages of CKD, overestimation of eGFR using the race coefficient can cause an under-recognition of CKD, and can lead to delays in diagnosis and failure to implement measures to slow its progression, such as minimizing drug-related nephrotoxic injury and iatrogenic acute kidney 
TABLE 2 Health Systems That Have Eliminated the Race Coefficient

\begin{tabular}{ll}
\hline Health Systems & Veterans Health Administration Affiliate \\
\hline Beth Israel Deaconess Medical Center, MA & Veterans Affairs Boston Healthcare System \\
\hline Mass General Brigham, MA & Veterans Affairs Boston Healthcare System \\
\hline Denver Health and Hospital Authority, CO & None \\
\hline Lifespan/Care New England, Warren Alpert School of Medicine, RI & Providence VA Medical Center \\
\hline NYU Langone Health, NY & Veterans Affairs New York Harbor Healthcare System \\
\hline $\begin{array}{l}\text { San Francisco General Hospital/San Francisco Department of Public } \\
\text { Health, CA }\end{array}$ & None \\
\hline University of California, San Francisco, CA & San Francisco Veterans Affairs Medical Center \\
\hline University of Washington, WA & Veterans Affairs Puget Sound Health Care System \\
\hline UW Health, WI & William S. Middleton Memorial Veterans Hospital \\
\hline Vanderbilt School of Medicine/Vanderbilt University Medical Center, TN & Tennessee Valley Healthcare System \\
\hline Barnes-Jewish Hospital, MO & None \\
\hline Rush University Medical Center, IL & None
\end{tabular}

injury. Consequently, a patient with an overestimated eGFR may suffer an accelerated progression to ESKD and premature mortality from cardiovascular disease. ${ }^{23}$

In advanced CKD stages, eGFR overestimation may result in delayed referral to a nephrologist (recommended at eGFR $<30 \mathrm{~mL} / \mathrm{min} / 1.73 \mathrm{~m}^{2}$ ), nutrition counseling, renal replacement therapy education, timely referral for renal replacement therapy access placement, and transplant evaluation (can be listed when eGFR $\left.<20 \mathrm{~mL} / \mathrm{min} / 1.73 \mathrm{~m}^{2}\right) .{ }^{16,24,25}$

In the Clinical Vignette, it is clear from the information presented that Mr. C's concerns are well-founded. Table 1 presents the impact on eGFR caused by the race coefficient using the MDRD and CKD-EPI equations. In many VA systems, this overestimation would prevent him from being referred for a kidney transplant at this visit, thereby perpetuating racial health disparities in kidney transplantation.

\section{Concerns About Removal of Race From eGFR Calculations}

Opponents of removing the race coefficient assert that a lower eGFR will preclude some patients from qualifying for medications such as metformin and certain anticoagulants, or that it may result in subtherapeutic dosing of drugs such as antibiotics and chemotherapeutic agents. ${ }^{26}$ These recommendations are in place for patient safety, so conversely maintaining the race coefficient and overestimating eGFR will expose some patients to medication toxicity. Another fear is that lower eGFRs will have the unintended consequence of limiting the kidney donor pool. However, this can be prevented by following current guidelines to use mGFR in settings where accurate GFR is imperative. ${ }^{16}$ Additionally, some nephrologists have expressed concern that diagnosing more patients with advanced stages of CKD will result in inappropriately early initiation of dialysis. Again, this risk can be mitigated by ensuring that nephrologists consider multiple clinical factors and data points, not simply eGFR when deciding to initiate dialysis. Also, an increase in referrals to nephrology may occur when the race coefficient is removed and increased wait times at some VA medical centers could be a concern. An increase in appropriate referrals would show that removing 
the race coefficient was having its intended effect-more veterans with advanced CKD being seen by nephrologists.

When considering the lack of biological plausibility, inaccuracy, and the clinical harms associated with the use of the race coefficient in eGFR calculations, the benefits of removing the race coefficient from eGFR calculations within the VA far outweigh any potential risks.

\section{A CALL FOR EQUITY The National Conversation on Race and eGFR}

To advance health equity, members of the medical community have advocated for the removal of the race coefficient from eGFR calculations for years. Beth Israel Deaconess Medical Center was the first establishment to institute this change in 2017. Since then, many health systems across the country that are affiliated with Veterans Health Administration (VHA) medical centers have removed the race coefficient from eGFR equations (Table 2). Many other hospital systems are contemplating this change.

In July 2020, the NKF and the ASN established a joint task force dedicated to reassessing the inclusion of race in eGFR calculations. This task force acknowledges that race is a social, not biological, construct. ${ }^{12}$ The NKF/ASN task force is now in the second of its 3-phase process. In March 2021, prior to publication of their phase 1 findings, they announced "(1) race modifiers should not be included in equations to estimate kidney function; and (2) current racebased equations should be replaced by a suitable approach that is accurate, inclusive, and standardized in every laboratory in the United States. Any such approach must not differentially introduce bias, inaccuracy, or inequalities." 27

\section{Health Equity in the VHA}

In January 2021, President Biden issued an executive order to advance racial equity and support underserved communities through the federal government and its agencies. The VHA is the largest integrated health care system in the United States serving 9 million veterans and is one of the largest federal agencies. As VA clinicians, it is our responsibility to examine the evidence, consider na- tional guidance, and ensure health equity for veterans by practicing unbiased medicine. The evidence and the interim guidance from the NKF-ASN task force clearly indicate that the race coefficient should no longer be used. ${ }^{27}$ It is imperative that we make these changes immediately knowing that the use of race in kidney function calculators is harming Black veterans. Similar to finding evidence of harm in a treatment group in a clinical trial, it is unethical to wait. Removal of the race coefficient in eGFR calculations will allow VHA clinicians to provide timely and high-quality care to our patients as well as establish the VHA as a national leader in health equity.

\section{VISN 12 Leads the Way}

On May 11, 2021, the VA Great Lakes Health Care System, Veterans Integrated Service Network (VISN) 12, leaders responded to this author group's call to advance health equity and voted to remove the race coefficient from eGFR calculations. Other VISNs should follow, and the VHA should continue to work with national leaders and experts to establish and implement superior tools to ensure the highest quality of kidney health care for all veterans.

\section{Acknowledgments}

The authors would like to thank the medical students across the nation who have been leading the charge on this important issue. The authors are also thankful for the collaboration and support of all members of the Jesse Brown for Black Lives (JB4BL) Task Force.

\section{Author affiliations}

Marci Laragh, Bijal Jain, Ambareen Khan, and Natasha Nichols are Attending Physicians; Cheryl Conner is the Section Chief for Hospital Medicine; Sheryl Lowery is an Inpatient Pharmacy Clinical Pharmacy Specialist; Jane Weber is a Nurse Practitioner Section of Palliative Care; and Samantha White is Facility Transplant Coordinator; all at the Jesse Brown Veterans Affairs Medical Center in Chicago, Illinois. Janine Steffan is an Internal Medicine Resident; and Bijal Jain and Natasha Nichols are Assistant Professors, Department of Medicine; and all at Northwestern University Feinberg School of Medicine. Marci Laragh, Cheryl Conner and Ambareen Khan are Clinical Assistant Professors of Medicine, and Sheryl Lowery is Adjunct Clinical Assistant Professor School of Pharmacy; all at the University of Illinois at Chicago.

\section{Author disclosures}

The authors report no actual or potential conflicts of interest with regard to this article.

\section{Disclaimer}

The opinions expressed herein are those of the authors and do not necessarily reflect those of Federal Practitioner, Frontline Medical Communications Inc., the US Government, or any of its agencies. 


\section{References}

1. American Medical Association. New AMA policies recognize race as a social, not biological, construct. Published November 16, 2020. Accessed July 16, 2021. www.ama -assn.org/press-center/press-releases/new-ama-policies -recognize-race-social-not-biological-construct

2. Bennett L. The Shaping of Black America. Johnson Publishing Co; 1975

3. David R, Collins J Jr. Disparities in infant mortality: what's genetics got to do with it? Am J Public Health. 2007;97(7):1191-1197. doi:10.2105/AJPH.2005.068387

4. Centers for Disease Control and Prevention. Media statement from CDC director Rochelle P. Walensky, MD, MPH, on racism and health. Published April 8, 2021. Accessed July 16, 2021. https://www.cdc.gov/media/releases/2021 /s0408-racism-health.html

5. Bonham VL, Green ED, Pérez-Stable EJ. Examining how race, ethnicity, and ancestry data are used in biomedical research. JAMA. 2018;320(15):1533-1534. doi:10.1001/jama.2018.13609

6. Kaplan JB, Bennett T. Use of race and ethnicity in biomedical publication. JAMA. 2003;289(20):2709-2716. doi:10.1001/jama.289.20.2709

7. Braun L, Wentz A, Baker R, Richardson E, Tsai J. Racialized algorithms for kidney function: Erasing social experience. Soc Sci Med. 2021;268:113548. doi:10.1016/j.socscimed.2020.113548

8. Vyas DA, Eisenstein LG, Jones DS. Hidden in plain sight - reconsidering the use of race correction in clinical algorithms. N Engl J Med. 2020;383(9):874-882. doi:10.1056/NEJMms2004740

9. Levey AS, Bosch JP, Lewis JB, Greene T, Rogers N, Roth D. A more accurate method to estimate glomerular filtration rate from serum creatinine: a new prediction equation. Modification of Diet in Renal Disease Study Group. Ann Intern Med. 1999;130(6):461-470. doi:10.7326/0003-4819-130-6-199903160-00002

10. National Kidney Foundation and American Society of Nephrology. Establishing a task force to reassess the inclusion of race in diagnosing kidney diseases. Published July 2, 2020. Accessed May 10, 2021. https://www.kidney.org /news/establishing-task-force-to-reassess-inclusion-race -diagnosing-kidney-diseases

11. Norton JM, Moxey-Mims MM, Eggers PW, et al. Social determinants of racial disparities in CKD. J Am Soc Nephrol. 2016;27(9):2576-2595. doi:10.1681/ASN.2016010027

12. Delgado C, Baweja M, Burrows NR, et al. Reassessing the Inclusion of Race in Diagnosing Kidney Diseases: An Interim Report from the NKF-ASN Task Force. J Am Soc Nephrol. 2021;32(6):1305-1317. doi:10.1681/ASN.2021010039

13. Suarez J, Cohen JB, Potluri V, et al. Racial disparities in nephrology consultation and disease progression among veterans with CKD: an observational cohort study. J Am Soc Nephrol. 2018;29(10):2563-2573. doi:10.1681/ASN.2018040344

14. McClellan WM, Warnock DG, Judd S, et al. Albuminuria and racial disparities in the risk for ESRD. J Am Soc Nephrol. 2011;22(9):1721-1728. doi:10.1681/ASN.2010101085

15. Zelnick LR, Leca N, Young B, Bansal N. Association of the estimated glomerular filtration rate with vs without a coef- ficient for race with time to eligibility for kidney transplant. JAMA Netw Open. 2021;4(1):e2034004. Published 2021 Jan 4. doi:10.1001/jamanetworkopen.2020.34004

16. Kidney Disease Improving Global Outcomes. KDIGO 2012 clinical practice guideline for the evaluation and management of chronic kidney disease. Published January 2013. Accessed July 16, 2021. https://kdigo.org/wp-content /uploads/2017/02/KDIGO_2012_CKD_GL.pdf

17. Sehgal AR. Race and the false precision of glomerular filtration rate estimates. Ann Intern Med. 2020;173(12):10081009. doi:10.7326/M20-4951

18. Bukabau JB, Sumaili EK, Cavalier E, et al. Performance of glomerular filtration rate estimation equations in Congolese healthy adults: the inopportunity of the ethnic correction. PLoS One. 2018;13(3):e0193384. Published 2018 Mar 2. doi:10.1371/journal.pone.0193384

19. van Deventer HE, George JA, Paiker JE, Becker PJ, Katz IJ. Estimating glomerular filtration rate in black South Africans by use of the modification of diet in renal disease and Cockcroft-Gault equations. Clin Chem. 2008;54(7):1197-1202. doi:10.1373/clinchem.2007.099085

20. Sagou Yayo É, Aye M, Konan JL, et al. Inadéquation du facteur ethnique pour l'estimation du débit de filtration glomérulaire en population générale noire-africaine : résultats en Côte d'Ivoire [Inadequacy of the African-American ethnic factor to estimate glomerular filtration rate in an African general population: results from Côte d’Ivoire]. Nephrol Ther. 2016;12(6):454-459. doi:10.1016/j.nephro.2016.03.006

21. Zanocco JA, Nishida SK, Passos MT, et al. Race adjustment for estimating glomerular filtration rate is not always necessary. Nephron Extra. 2012;2(1):293-302. doi:10.1159/000343899

22. Flamant M, Vidal-Petiot E, Metzger M, et al. Performance of GFR estimating equations in African Europeans: basis for a lower race-ethnicity factor than in African Americans. Am J Kidney Dis. 2013;62(1):182184. doi:10.1053/j.ajkd.2013.03.015

23. Shlipak MG, Tummalapalli SL, Boulware LE, et al. The case for early identification and intervention of chronic kidney disease: conclusions from a Kidney Disease: Improving Global Outcomes (KDIGO) Controversies Conference. Kidney Int. 2021;99(1):34-47. doi:10.1016/j.kint.2020.10.012

24. Eneanya ND, Yang W, Reese PP. Reconsidering the consequences of using race to estimate kidney function. JAMA. 2019;322(2):113-114. doi:10.1001/jama.2019.5774

25. Diao JA, Wu GJ, Taylor HA, et al. Clinical implications of removing race from estimates of kidney function. JAMA. 2021;325(2):184-186. doi:10.1001/jama.2020.22124

26. Diao JA, Inker LA, Levey AS, Tighiouart H, Powe NR, Manrai AK. In search of a better equation - performance and equity in estimates of kidney function. $\mathrm{N}$ Engl $\mathrm{J}$ Med. 2021;384(5):396-399. doi:10.1056/NEJMp2028243

27. National Kidney Foundation and American Society of Nephrology. [Letter]. Published March 05, 2021. Accessed July 16, 2021. https://www.asn-online.org/g/blast/files /NKF-ASN-eGFR-March2021.pdf

28. Waddell K. Medical algorithms have a race problem. Consumer Reports. September 18, 2020. Accessed July 16, 2021. https://www.consumerreports.org/medical-tests /medical-algorithms-have-a-race-problem 